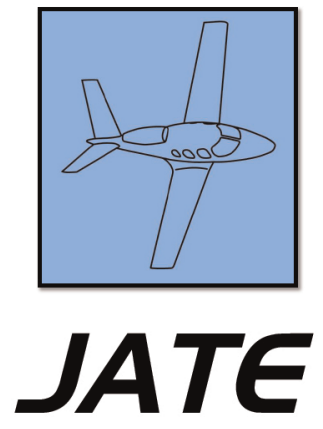

Journal of Aviation Technology and Engineering 1:1 (2011) 11-18

DOI: $10.5703 / 1288284314631$

\title{
The Black Experience in Business Aviation: An Exploratory Case Study
}

\author{
Tara L. Harl \\ St. Cloud State University \\ Phil Roberts \\ PAR Travel Tech, Inc.
}

\begin{abstract}
Despite a rich heritage of interest in aviation as a career choice, Blacks have been underrepresented across all three areas of aviation in the United States: airline/air transport, military, and general/business aviation. The lack of interest in aviation careers by Blacks has not been the issue; societal obstacles, historical ignorance of the Black aviation experience, and an industry that traditionally closed most doors to professional aviation careers for minorities have been the culprits. Business and corporate aviation (corporate flight departments/ service providers) in particular has experienced low entrance and retention numbers for Black professionals, a reflection of the wider civilian aviation industry. An exploratory single case study, focusing on the experiences of Blacks employed in the world of business aviation, was completed and is described herein. This study design was chosen due to the lack of research on the topic in the existing literature. The data gathered advocates for future research across five major areas in order to further the knowledge and understanding of Black representation, not only in business aviation, but in the wider aviation industry as a whole.
\end{abstract}

Keywords: minorities in aviation, blacks in aviation, aviation diversity, workforce development issues in aviation

\section{Introduction}

Black professional representation across the three arenas of United States aviation-airline/air transport, military, and general aviation - has traditionally been weak, despite minorities having had a strong interest in aviation careers since the beginning of powered flight (Seideman \& Spanovick, 1991). Only one study has addressed these low numbers of Blacks in the civilian industry, while aviation periodicals scarcely reported Black aviation news during most of the last century (NAS, 1997). The number of professional aviation role models within the Black community remained low until the 1980s (Blackwell, 1981). Darity and Mason (1998) noted the lack of Blacks within the airline industry had rarely been addressed unless, or until, a complaint or lawsuit had been filed (Colorado v. Continental Airlines, 1963).

Alderfer and Thomas (1988) discovered that two decades after the Civil Rights Act of 1964, only a modest increase in research on racial dynamics in organizational behavior had been undertaken. When the corporate world (as a whole) began 
to address the issue of Black representation, Henderson (1995) noted that transportation service departments of corporate America (business aviation) were largely overlooked. The National Academies of Sciences (NAS, 1997) reported that solid numbers for business aviation do not exist. The National Business Aviation Association (NBAA) does not track these numbers (NBAA, 2009).

This study focused on the experience of Black aviation maintenance technicians, pilots, flight attendants, dispatchers, and management personnel with two to five years of experience, currently employed in business aviation. Only thirty-five individuals could be found over the five years researchers worked to locate names. When dealing with a very small or nonexistent population, Fraenkel and Wallen (2003) suggest the size be large enough to bring credibility to the study yet small enough to allow for adequate depth, detail, and richness for the case; this study's population size was dictated by the number of Blacks employed in business aviation. It was undertaken within a one-year timeframe, as experts recommend an exploratory case study should be shorter than other case studies in order to capture precise, clear, and current information (MacNealy, 1997; Yin, 2003).

\section{Research Technique}

The exploratory case study utilizes a very narrow focus; it deals with a single unit or group of related persons (MacNealy, 1997). This design is advocated when literature about a rare, unique, or unresearched topic is nonexistent (Yin, 1994; Merriam, 1998; Marshall \& Rossman, 1999). The validity of the exploratory case study is often criticized due to its uniqueness and a misunderstanding of the rigor of design. There is a concern that only data that support the interpretations of the researcher are reported. This concern required the researchers in this study to give all the more attention to detail in design, implementation, analysis, and reporting of findings. Hypotheses building was difficult due to a lack of available literature, resulting in a weak knowledge base that did not lend itself to the development of theoretical statements or constructs from which survey or interview questions could be developed (Kennedy, 1999; Yin, 2003).

Yin's (2003) template for exploratory case studies required strict adherence to clarifying (a) what is to be explored, (b) the purpose of the exploration, and (c) the criteria by which the exploration will be judged. Empowerment evaluation, a technique to ensure quality of finished product, brought a coresearcher into collaboration with the primary researcher in: (1) primary question development, (2) evaluation design, (3) preferred data collection method, and (4) publication standards (Yin, 1997a).

\section{Title of the Study}

Member checking, an exploratory case study technique whereby participants are asked observations and opinions of key research techniques, was utilized, before the study began (Creswell \& Miller, 2000; Yin, 2003). When asked their choice of the title, Blacks in Business Aviation or African Americans in Business Aviation, the majority of participants favored the term Blacks in Business Aviation. Majority opinions for the choice are summarized by this reflection from Participant 32:

For me, the term African American denotes an African that becomes an American citizen. I am an American of African descent. When I hear the term African American, it usually is coming from a White person who is unfamiliar or uncomfortable with the Black culture.

\section{Ethical Concerns}

Both researchers, being White and having business aviation careers spanning over three decades, utilized a suggestion by Lee et al. (1999) that qualitative researchers must identify particular bias during research reflecting on who they represent in the inquiry, and be sensitive to personal biography and bias, which may be brought to the study in order for validity threats to be minimized (Marshall \& Rossman, 1999). The fact that the researchers are White (one is considered a minority in aviation) initially brought surprise from participants, then a gratefulness that someone was finally addressing the issue of Black representation in business aviation. A foundation of trust was established with participants that produced a strong willingness to share personal reflections (Alderfer \& Brown, 1972; Alderfer \& Smith, 1982). Confidentiality agreements were signed; the names of participants and corporations of employment remained anonymous (Kleinsasser, 2000).

\section{Review of Literature}

To the best of the researchers' knowledge, there have been no studies undertaken in this area, and thus a review of literature could not be reported. Merriam (1998) advised that a claim of no literature may lead the reader to assume the topic is not worth studying, there may be no way to study it, the search is too narrow, or the research is flawed. At a minimum, studies tangentially related should be presented so that the situation can be fully comprehended.

\section{Studies Tangentially Related}

The United States Congress Subcommittee of the House Committee on Government Operations held hearings in 1986 and 1987 on Black representation within the airline industry (NAS, 1997). Some key findings concluded:

1. Airline/air carrier industry studies are few and fall mostly in the world of economics; airlines often fail to incorporate affirmative action policies. 
2. The Federal Contract Compliance Programs had done a poor job of monitoring airline industry affirmative action compliance.

The National Academy of Sciences (NAS, 1997) 1996 Committee on Education and Training for Civilian Aviation Careers assessed military downsizing's effect on the civilian aviation candidate pool. The report did not determine whether racial representation was reflected within the numbers. However, it noted that retention of minorities in aviation would require advocacy, citing "hope" that the awareness of the small percentage of Blacks in aviation would somehow disturb the conscience of the aviation industry, though a change of attitude would likely be unrealistic given the lack of knowledge of Black aviation history within the aviation industry. According to the report, "as will become apparent time and again ..., quantifying what is happening in the aviation workforce and its training paths is surprisingly difficult" (NAS, 1997, p. 15).

The business aviation industry comprised one small paragraph within the larger report.

Falter's (2000) study of the human resource management techniques of Duncan Avionics, a service provider to business aircraft operators, was the only published research found that focused strictly on business aviation human resource policies. It did not produce data on issues of minority attraction or retention; race was not a factor in data gathering.

Foster's (2003) study addressing women and other minority representation in maintenance careers addressed the aviation industry as a whole and did not focus on business aviation.

Tuney (2004) addressed the low numbers for diversity in aviation training facilities yet did not specifically address business aviation, or attracting and retaining Blacks.

Military studies from the 1940s to the present addressing integration and the Black experience in the armed forces were not utilized because the military world, due to its very nature and the studies undertaken, does not reflect the hiring or training practices of the civilian world, and because some studies have not been released to the public for dissemination (Butler, 1992).

\section{Methodology}

Exploratory case studies focus on a single phenomenon in a real-life context utilizing multiple sources of evidence converging to include an examination of contemporary issues and the possibility to discover while in the process of research. They do not have the benefit of prior theoretical propositions (Stake, 1995; Yin, 1999; Yin, 2003). Furthermore, the instrumentation, observation methods, and modes of analysis to address validity and reliability demand strict adherence to guidelines established by experts (Yin, 1994; Lee, Mitchell, \& Sablynski, 1999). The three tenets of qualitative research method were satisfied with the case study design: (1) describing, (2) understanding, and (3) explaining (Tellis, 1997).

\section{Data Collection}

Two levels of sampling are recommended for exploratory case studies: (a) one for the case, and (b) one for the study sample of the case.

\section{Sampling level one: initial question asked}

Patton (1987) suggested an initial question be asked to open the door of understanding just enough to glimpse what is happening. It should be semi-structured, linking the roots of the unanswered dilemma(s) to the existing literature, and should open a door to whatever might develop when a small sample size is used to acquire in-depth and intimate knowledge of a limited group (Amber et al., 1995; Merriam, 1998). Thirty-five participants were asked the open- ended question: What has been your experience being Black in business aviation? They were instructed to write rich descriptions of the world of business aviation and articulate impressions of their career paths, allowing the researchers to gain insight into participants' work experience (Creswell \& Miller, 2000; Yin, 2003). Twenty-one turned in reflective pieces, including sixteen males and five females.

The authentic voice of participants (Ambert, Adler, Adler, \& Detzner, 1995; Stake, 1995) was uncovered as the research technique addressed what is occurring and how it is occurring. The study utilized three recommended general characteristics: (1) the research took place in a natural setting (participants wrote their essays in private), (2) the data were derived from the perspective of the participants (no leading questions were asked), and (3) the research was flexible to match the fluidity of the research situation (participants were given three months to turn in their reflections; most wrote while "on the road" with their laptops).

Most participants began their reflections by relaying their experiences before entering the business aviation career field. They shared stories of who they are, what family values had been instilled in them, how growing up in the military broadened their perspectives, and how their love of aviation began in childhood. This was not the question asked of the participants, yet these were often the first answers given. As noted in Career Reflective Piece 25, "before I can reflect on my career as a corporate pilot, I feel it is important to capture the root cause of my desire to fly."

\section{Interview question development}

The reflective pieces were studied to determine patterns from which interview questions could be developed for Sampling Level Two. In-depth interview questions were built from the personal reflective summaries structured around Patton's (1987) six recommended theme areas for question development:

Area 1: Experience/Behavior Themes

Area 2: Opinion/Belief Themes

Area 3: Feelings Themes

Area 4: Knowledge Themes 
Area 5: Personal Reflection Themes

Area 6: Background demographic themes

Professional career patterns and attitudes about the research emerged along with demographic information: (a) almost all participants had grown up in the Northern or Western United States; (b) a few had immigrated to the United States as children, then grew up in Northern regions; (c) many grew up in the military; (d) most have college degrees, seven with degrees in science; (e) almost all grew up in families that value education; (f) almost all mentioned a love of aviation since childhood; (g) most of their families were economically comfortable when they were growing up; and (h) many had career military experience before entering business aviation.

Area six then changed into two areas and eighth and ninth areas were added. Experts had suggested additional themes might develop as participants' reflections unfolded (Patton, 1987). The researchers now had revised areas for question development:

Area 6: Items Declared Significant

Area 7: Items Omitted/Not Said, Yet Implied

Area 8: Background Demographics

Area 9: Participants' Attitudes Concerning This Research

Under each of the nine categories data from the career reflective pieces were coded on a computer spreadsheet (Mousley, Sullivan, Waywood, 1997) for (1) frequency, the number of times an item appeared within the data; (2) omission, items which never appeared in the data; and (3) declaration, items presented or declared significant by the participants. The items were then organized into categories for interview question development (Lecompte, 2000; Yin, 2003). The questions were semi-structured or open ended, as it was the hope of the researchers to link the roots of the unanswered dilemma(s) to the existing literature, yet not to lead+ the participants toward any one answer (Patton, 1987). Explanation for question development was presented to participants of the study (Amber et al., 1995; Lee et al., 1999; Yin, 2003). Archival records were not used since participants did not produce journals, logs, or diaries.

Bias, which could have developed, was avoided by using recommended approaches to data collection: (a) copies were made of all data, (b) all notes were filed in order of dates created, (c) documents were cataloged and labeled, and (d) reflective pieces were co-reviewed to compare data collected (LeCompte, 2000). Field notes of feelings, intuition, and hunches concerning the research and documentation of the work in progress were written and filed. Labeled field packets of documents were also stored (Patton, 1990; Soy, 1997; LeCompte, 2000; Yin, 2003). Interview questions were then established for each of the nine theme areas.

\section{Sampling level two: interview protocol pilot study}

A pilot interview was undertaken to test the timing of the questions and the tone for the interview; all questions flowed and developed a rhythm. A few changes were made, mostly for grammar. It was determined that interviews would require two to two-and-a-half hours each. The data retrieved from the pilot study were rich and detailed. The interview questions were revised and prepared for the interview process.

\section{Sampling level two: interview of participants}

Participants were chosen for follow up in-depth interviews based on: (a) years working in business aviation, (b) articulation of impressions of career experience, and (c) willingness to write a descriptive essay that allowed the researchers to gain insight into work experience (Yin, 2003). The Cross-case (cross interview) technique was utilized and answers to common questions asked of multiple participants were grouped together for common answers (Patton, 1990).

\section{Data Gathering}

Data gathering utilized six recommended steps: (1) determination of the research question; (2) propositions, if any; (3) unit of analysis; (4) collecting the data; (5) logic linking data to propositions; and (6) criteria for interpreting the findings (Creswell \& Miller, 2000; Yin, 2003). While determining the research question, the history of Black participation within aviation was presented with particular note to a lack of participation within business aviation. This exploratory case study did not have the luxury of published literature. The unit of analysis was defined by the initial question of what, and by that which was learned from the answers to this question. Data collection was undertaken in a specific time frame so as to create a snapshot. The data were linked to the purpose of the study and the criteria from which the study was judged were explained. Rigorous guidelines for validity and reliability were utilized in interpreting findings.

Since exploratory case studies are utilized to lay the foundation for research in previously unexplored territory, measurement of facial reactions or recall of a situation during interviews is not required and was not used for this study (Yin, 2003). Data were collected from the researchers' offices via telephone and personal interviews at facilities on or near the participants' based airports of employment. The interviews were recorded and required a period of two-and-a- half months to complete. Data collected for evidence were gleaned from two of the six recommended sources: (1) documents and (2) interviews; the other four-archival records, direct observation, participant observation/artifacts/ diaries, and logs or journals-were not used (Patton, 1990; Yin, 1994; Stake, 1995).

\section{Coding Procedures}

As mentioned previously, items were coded for frequency, omission, and declaration. Data were color-coded 
upon arrival, transcripts were reorganized with defined colored bold headings/page separations between headings, and each of the nine areas of questions was assigned a different color. The transcripts were then color coded by sections to define a separation between themes. This allowed the researchers to visually jump from transcript to transcript easily while comparing and contrasting data (Lecompte, 2000; Yin, 2003).

\section{Data Analysis}

Yin's (2003) template for data analysis was employed across the four suggested principles: (1) analysis showing all evidence had been attended; (2) major rival interpretations were considered; (3) analysis addressed the most important issue of the study and did not find the study being detoured on another route; and (4) researchers used prior expert knowledge of the issue, demonstrating awareness and discourse concerning the research topic. To ensure trustworthiness of findings, the suggested use of member checking in data analysis was employed for a second time. Participants approved descriptive language used by the researchers by reviewing transcripts of their interviews to understand how the researchers came to transform data into concepts and confirmed that printed words reflected the participants' perspectives. Revisions were made where needed (Baxter and Eyles, 1997; Creswell \& Miller, 2000; \& Yin 2003).

\section{Analysis model}

Yin (2003) advocated the use of one or more of three models to ensure readers understood what will be analyzed and why it was accomplished. The three models are: (1) development of case descriptions, (2) relying on theoretical propositions, and (3) considering rival explanations. To comply with the first model, the study defined what was to be explored, the purpose of the exploration, and the criteria that judged the exploration. The second and third models were not used, as there is no published literature on Blacks in business aviation and therefore no theoretical propositions or rival explanations.

Yin (2003) suggested researchers utilize at least one of five reanalysis procedures for exploratory case studies. This research utilized cross-case synthesis. In cross-case synthesis, multiple cases were conducted independently and were a predesigned part of the same study. The study did not use pattern matching, which compares empirically-based patterns with predicted patterns, usually to help strengthen internal validity; time-series analysis, found within experiments and quasi-experiments when participant-observer studies follow time-series designs; logic model, the use of matching empirically observed events with theoretically predicted ones; or explanation building, when the researcher wants to explain phenomena to stipulate a presumed set of causal links within an explanatory case study.

\section{Data Reporting}

The study used two of Yin's (2003) recommended six techniques for data reporting: linear-analytic, a standard approach utilized when the topic is identified, review of literature is undertaken, methodology is described, findings from the data are analyzed, and conclusions written; and reflexivity engaged before, during, and after research across four critical junctures: (a) gaining access, (b) maintaining access, (c) drafting the research document, and (d) bringing the study to closure to counteract bias in order for the researchers to understand and critically examine the entire research process. The researchers consciously remembered where, what, and how the research was established, always being aware that the study was to report the world as the participants have witnessed it, not the researchers' reflections (Baxter \& Eyles, 1997). In the words of Participant 10 , "when you work in this aviation career field, you have to be mindful that not everyone is happy to see you. One of the things that I have also learned is to stop whining. They aren't going to listen to you. I even think it is going to make your situation worse. I am grateful for everything I have gone through....it only makes me stronger."

\section{Reliability and Validity}

Ensuring the reliability of this exploratory case study design and implementation required three procedures: (1) case study protocol, explaining all procedures and rules to participants throughout the study, beginning with the research question; (2) case-study database, filing documents in two separate collections: the data base and the report by researcher; and (3) cross-case synthesis, analyzing the interview transcripts as recommended across multiple cases, when individual cases are previously conducted independently and separately from the others (Yin, 2003).

Yin (2003) has shown that construct validity for an exploratory case study (literature is not available from which constructs may be built) is irrelevant; internal validity is not pertinent as causal relationships are not a feature of an exploratory study ( $\mathrm{x}$ led to event $\mathrm{y}$ ); and external validity, establishing the domain to which findings from a study can be generalized, is usually addressed when multiple case studies are utilized for theory development. Though this exploratory study did not address theory development, the instrument still demonstrated validity with implementation of four of the nine recommended techniques: (1) researcher reflexivity, in which participants were given background information on the career of the researcher, (2) member-checking, in which participants were asked personal observations and opinions of key research techniques, (3) thick/rich description, in which indepth data were reported by participants and follow-up interviews were conducted to validate the data; and (4) peer 
reviews, in which more than one researcher analyzed the data (Cresswell \& Miller, 2000).

The researchers were also aware of experimenter effect that could have threatened validity in the selection of participants and instruments, which, in turn, could have affected the outcome of the research (Yin, 2003). Further use of the validation techniques suggested for exploratory case studies, the peer reviewer and evaluation findings was engaged when both researchers listened to the tape recordings of the interviews for a second time while reading the transcripts, to concur with the findings (Patton, 1987; Patton, 1990; Yin, 1994).

\section{Findings}

\section{Area 1: Experience/Behavior}

Participants love the dynamic world of business aviation; effective mentoring and networking (membership in White professional organizations) have been vital tools for career success. Yet, many minority children are not being taught why these are vital skills in predominantly White industries. Also, Whites are not always cognizant of how lonely it can be for the only Black member within an organization.

a. White aviators' perceptions of Black aviators often reflect fear, ignorance, indifference, or a lack of knowledge of Black aviation history.

b. Love of aviation began in childhood, and family encouragement was a strong factor. Yet many had to learn the nuances of business aviation while on the job, which can be a tricky situation for a minority navigating a White environment.

c. Knowledge of the business aviation career field in minority communities is lacking; the Black aviation role model is not always available for Black children.

d. Racial issues within the aviation industry present a double-edged sword. All agreed that "knowing your technical stuff" and not using the race card was the best route for success. Lack of a proactive stand on racial issues by the NBAA is frustrating, yet many stated it might not be fair to expect one organization to fix the problems of a whole industry.

e. CEOs and upper management have demonstrated strong personal support for the Black aviator's presence, yet there is deep frustration among the participants at human resource departments' lack of realistic and effective policies.

\section{Area 2: Opinion/Belief}

a. The business aviation career field has brought value to the participants' lives and validated their skills; the sheer love of aviation and airplanes helps the participants maintain positive attitudes. Yet, most have had to work harder than Whites to prove their skills to industry.

b. The "good ole boy system" is changing very slowly because the business aviation community and Black aviation professionals have not addressed it collectively. Racism is the elephant in the room that nobody wants to recognize and many are uncomfortable discussing.

Area 3: Feelings

a. Most participants have been the first or only Black in their flight department and feel a pressure to represent the whole Black race to White aviators. They sense the sheer magnitude of what they have accomplished may be greater in that White professionals may have grown up with a sense of entitlement that the aviation industry would automatically accept them.

\section{Area 4: Knowledge}

a. While the business aviation world is primarily White, participants did not use race as a defining term for the culture of business aviation; almost all used management and technical terms.

b. Participants used the term professional standards instead of survival techniques when addressing how to handle racial issues.

\section{Area 5: Personal Reflection}

a. All stressed that skin color cannot be an issue when safety is the first mission of a team, yet minorities often have to accommodate Whites who are uncomfortable working with a minority on their team.

b. Many are frustrated with the low number of Blacks in aviation and with Whites who do not have knowledge of how or why Blacks were shut out of professional aviation opportunities for most of the $20^{\text {th }}$ century.

c. While military culture has shaped business aviation, the military's strong record on addressing racial issues has not flowed over into business aviation.

\section{Area 6: Items Declared Significant}

a. Participants knew from childhood that aviation was a White profession; other technical fields (engineering, 
medicine, etc.) have done a better job than aviation in attracting minorities.

b. Whites tend to respect any Black who can successfully navigate the business aviation world; aviators are self-selecting.

c. Many Whites don't understand why diversity is vital for the economic health of the whole aviation industry and why it complements many Fortune 500 corporations' mission/vision statements.

\section{Area 7: Items Omitted/Not Said Yet Implied}

a. Being a minority at work can often bring more stress upon home life.

b. HR departments often assume a region with a large Black population is attractive to the Black candidate while not considering the socio-economic composition of the Black population in that region of employment.

c. Most maintained a guarded reflection on race almost not wanting to admit that racism had reared its ugly head toward them. Participant 25 summarized it best:

America has a lot of prejudices about Blacks. You can see that when you are walking down the street. It is a burden because you have to face it. If you get stopped by a policeman you have to think that maybe something else is going on. I find that many Americans are pretty fairminded, when they get to know you they will understand who you are, but that doesn't necessarily mean they will understand your color if they happen to see you in the supermarket. In other words I understand that White people make exceptions about people that they accept.

\section{Area 8: Background Demographics}

Before the participants began to describe their experiences within business aviation, almost all divulged background demographics. This was not the question asked of the participants yet this was the first answer most chose to give.

\section{Area 9: Participants' Attitudes Concerning This Research}

The researchers did not seek reflection in this area yet noticed a deep well of anticipation and relief volunteered by participants that industry might finally begin to look into the issue of Black representation within the business aviation world and develop tools to address it.

\section{Conclusion}

The aviation industry, and those attracted to a career within it, reflects a passion focused on a single concept, flight, and the vehicle creating that possibility, the aircraft. An aviation career has sometimes been called a lifestyle and not a job. Perhaps the taproot of historical passion aviators all share might inspire the industry to roll up its sleeves and focus on the issue of diversification of its workforce, giving validation to the voices uncovered in this research, such as that of Participant 13:

It is, as with anybody, you would like to see more of your same kind of people around you, but going back to that . . . in this industry we kind of all have the same thoughts and love, the love of flying. We are just not the same skin color.

\section{Recommendations for Further Study}

\section{Demographics/Backgrounds}

The participants chose to open their career reflective pieces and to weave stories throughout their interviews of family background and the foundation it laid for their success in life, gifting them with the courage to enter, and tenacity to succeed, in a predominately White industry. What can be emulated by educators and family to empower young Black children to dream about aviation careers the way these participants did?

\section{Mentoring and Networking}

The role of mentors and networking is critical in business aviation, an industry that values who you know and who knows you. The role of the mentor is often overlooked when resources are given to technical training. Are young people being taught these vital skills, especially young Blacks, when it comes to finding their way in a White industry? Why has aviation not tackled this question when other technical industries have done a much better job of addressing the mentoring of young Blacks toward their field?

\section{The Black Experience throughout the Entire Aviation Industry}

A study of the wider aviation industry and how it can attract and retain more minorities is due for an update, with a sharper focus toward the Black community and its perceptions than the NAS study produced in 1997. Why do Blacks generally not consider aviation a viable career field? What can be done to change that mind-set? With many opportunities waiting for Blacks to enter and be promoted, why do they not take advantage of them within aviation? A step back to study the Black communities' impressions of aviation as a potential career path is long overdue. 


\section{Military}

The strong influence of the military, whether one was growing up as a child, or being on active duty, was a thread woven throughout the stories of the participants. What powerful forces to mentor future generations of Black aviation professionals did the United States lose when the Tuskegee Airmen were denied jobs within the growing airline industry after WWII? How can this country gain back that force to mentor for the current century?

\section{The Culture of Business Aviation}

Research has never defined the parameters of this world and its culture while fully admitting to being its own "bestkept secret." Business aviation struggles to define itself outside its own walls and, when crisis hits, scrambles to explain itself to the outer world (e.g., congressional pressure in 2008 for Ford, Chrysler and General Motors to sell their corporate aircraft). Business aviation needs to define itself in order to understand how that definition limits its ability to attract and retain minorities. Perhaps business aviation is not for everyone who might decide to enter aviation industry employment; numbers demonstrate that fact even among Whites. Yet, while corporate America's human resource departments are addressing diversification, and demanding that flight departments reflect the face of headquarters, business aviation managers struggle to find data and tools to assist them in addressing the issue.

\section{References}

Alderfer, C. P., \& Brown, D. L. (1972). Designing an "empathic questionnaire" for organizing research. Journal of Applied Psychology, $56,456-460$.

Alderfer, C. P., \& Smith, K. K. (1982). Studying inter-group relations embedded in organizations. Administrative Science Quarterly, 27, 3565.

Alderfer, C. P., \& Thomas, D. A. (1988). The significance of race and ethnicity for understanding organizational behavior. International Review of Industrial and Organizational Psychology, 1, 1-41.

Ambert, A. M., Adler, P. A., Adler, P., \& Detzner, D. F. (1997). Understanding and evaluating qualitative research. Journal of Marriage and the Family, 57, 879-893.

Baxter, J., \& Eyles, J. (1997). Evaluating qualitative research in social geography: Establishing "rigor" in interview analysis. Transactions of the Institute of British Geographers, 22, 505-525.

Blackwell, J. E. (1981). Mainstreaming outsiders: The production of Black professionals. Boston, MA: General Hall.

Butler, J. S. (1992). Affirmative action in the military. Annals of the American Academy of Political Social Science, 523, 196-206.
Cresswell, J. W., \& Miller, D. L. (2000). Determining validity in qualitative inquiry. Theory into Practice, 39, 124-130.

Colorado v. Continental Airlines, Inc., 372 U.S. 714 (Co. 1963).

Darity, W. A., \& Mason, P.L. (1998). Evidence on discrimination in employment: Codes of color, codes of gender. The Journal of Economic Perspective, 12, 63-90.

Falter, J. (2000). The company as family: Perceived strengths of Duncan Avionics. Unpublished doctoral dissertation, University of Nebraska, Lincoln.

Foster, Paul M, Jr. (2003). Recruiting women and minorities into aviation maintenance. Doctoral dissertation, Pepperdine University.

Fraenkel, J. R., \& Wallen, N. E. (2003). How to design and evaluate research in education. Boston, MA: McGraw-Hill.

Henderson, D. (1995). The drive for diversity. Air Transport World, 32, 33-39.

Kennedy, P. L., \& Luzar, E. J. (1999). Toward methodological inclusion: The case for case studies. Review of Agricultural Economics, 21, 579591.

Kleinsasser, A. M. (2000). Researchers, reflexivity, and good data: Writing to unlearn. Theory and Practice, 39, 155-162.

LeCompte, M. D. (2000). Analyzing qualitative data. Theory into Practice, 39, 146-154.

Lee, T. W., Mitchell, T. R., \& Sablynski, C. J. (1999). Qualitative research in organizational and vocational psychology, 1979-1999. Journal of Vocational Behavior, 55, 161-187.

MacNealy, M. S. (1997). Toward better case study research. Transactions on Professional Communication, 40, 182-196.

Marshall, C., \& Rossman, G. B. (1999). Designing qualitative research. Thousand Oaks, CA: Sage.

Merriam, S. B. (1998). Qualitative research and case study applications in education. San Francisco, CA: Jossey-Bass.

Mousley, J., Sullivan, P., \& Waywood, A. (1997). Using a computer in synthesis of qualitative data. Journal of Research in Mathematics Education, 9, 128-177.

National Academy of Sciences. (1997). Taking flight: Education and training for aviation careers. Washington, DC: Author.

National Business Aviation Association. (2009). Retrieved February 11, 2009, from http://www.nbaa.org/

Patton, M. Q. (1987). How to use qualitative methods in evaluation. Newbury Park, CA: Sage.

Patton, M. Q. (1990). Qualitative evaluation and research methods. Newbury Park, London: Sage.

Seidenman, P., \& Spanovich, D. (1991). Illegal discrimination and pilot hiring. Career Pilot, 29-40.

Soy, S. K. (1997, Spring). The case study as a research method. Unpublished paper presented at University of Texas, Austin, TX.

Stake, R. E. (1995). The art of case study research. Thousand Oaks, CA: Sage.

Tellis, W. (1997). Introduction to case study. The Qualitative Report, 3.

Turney, M. A. (Ed.). (2004). Tapping diverse talent in aviation: Culture, gender and diversity. Brookfield, VT: Ashgate.

Yin, R. (1994). Case study research design and methods. Thousand Oaks, CA: Sage.

Yin, R. (1997a). Case study evaluations: a decade of progress? New Directions for Evaluation, 76, 69-78.

Yin, R. (1999). Enhancing the quality of case studies in health services research. Health Service Research, 34, 1209-1224.

Yin, R. (2003). Case study research design and methods (5 $5^{\text {th }}$ ed.). Thousand Oaks, CA: Sage. 